\section{INDUCCIÓN DE PROEMBRIONES SOMÁTICOS EN AVE DEL PARAÍSO (Strelitzia reginae Banks)}

\author{
SOMATIC PROEMBRYO INDUCTION IN \\ BIRD OF PARADISE \\ (Strelitzia reginae Banks)
}

\section{Amaury Martín Arzate Fernández ${ }^{1^{*}}$, José Luis Piña Escutia $^{1}$ e Hilda Araceli Zavaleta Mancera ${ }^{2}$}

\begin{abstract}
${ }^{1}$ Laboratorio de Biología Molecular, Facultad de Ciencias Agrícolas, Universidad Autónoma del Estado de México. Campus Universitario "El Cerrillo". Carr. Toluca-Ixtlahuaca, km. 11.5 entronque al Cerrillo Piedras Blancas. 50200, Toluca, Estado de México. ${ }^{2}$ Programa de Botánica, Colegio de Postgraduados. Km. 36.5 Carr. México-Texcoco. 56230, Montecillo, Estado de México.

*Autor para correspondencia (amaury@uaemex.mx)
\end{abstract}

\section{RESUMEN}

El ave del paraíso (Strelitzia reginae Banks) es una planta ornamental que por su belleza es altamente cotizada como flor de corte. Se propaga por semilla y por división de matas, aunque ambos métodos son muy lentos. La multiplicación de plantas in vitro vía embriogénesis somática, ha sido exitosamente establecida en muchas especies ornamentales. Para $S$. reginae no existen reportes de su propagación mediante dicho proceso ya que presenta serios problemas de oscurecimiento de los explantes cultivados. En este trabajo se estableció un procedimiento para la inducción de proembriones somáticos (PES) a partir de fragmentos (explantes) del nudo cotiledonar de plántulas de $30 \mathrm{~d}$ de edad. A los cinco meses de incubación, los explantes cultivados en oscuridad produjeron PES en el medio Murashige y Skoog a $100 \%$ y $50 \%$ de su concentración, suplementado con 2,4-D $\left(0.5\right.$ a $\left.2.0 \mathrm{mg} \mathrm{L}^{-1}\right)$, sacarosa $\left(30 \mathrm{~g} \mathrm{~L}^{-1}\right)$ y carbón activado $\left(0.1 \mathrm{~g} \mathrm{~L}^{-1}\right)$. Los PES crecieron y formaron estructuras de 5 a 6 mm de longitud, cuyo extremo distal presentó una organización celular comparable a la de un meristemo de raíz pero sin centro quiescente. Los cortes histológicos no evidenciaron la presencia de un meristemo apical de brote, lo cual pudo haber causado que los proembriones in vitro no completaran su desarrollo.

Palabras clave: Strelitzia reginae, 2,4-D, cultivo in vitro, proembrión somático, callo embriogénico.

\section{SUMMARY}

The bird of paradise (Strelitzia reginae Banks) is a beautiful ornamental plant highly valued as cut flower. It is propagated by seed or division of old plants, although both methods are very slow. The in vitro propagation of plants through somatic embryogenesis has been established successfully for many ornamentals species. There are no reports about this process in $S$. reginae because this species presents serious problems of browning in the cultured explants. In this work we established a procedure for the induction of somatic proembryos (SPE) using cotyledon node fragments from plantlets 30 d old. After five months of incubation, explants cultivated on dark conditions produced SPE in Murashige and Skoog medium at 100 and $50 \%$ strength, supplemented with 2,4-D $\left(0.5\right.$ to $\left.2.0 \mathrm{mg} \mathrm{L}^{-1}\right)$, sucrose $\left(30 \mathrm{~g} \mathrm{~L}^{-1}\right)$ and activated charcoal $\left(0.1 \mathrm{~g} \mathrm{~L}^{-1}\right)$. The SPE grew and formed structures $5-6 \mathrm{~mm}$ long, whose distal tip presented a root meristem-like cellular organization which lacked a quiescent centre. The absence of a shoot meristem in the SPE prevented the further in vitro development of proembryos.

Index words: Strelitzia reginae, 2,4-D, in vitro culture, somatic proembryo, embryogenic callus.

\section{INTRODUCCIÓN}

El ave del paraíso (Strelitzia reginae Banks) es una planta ornamental exótica que por su belleza alcanza un alto precio en los mercados nacional e internacional. Se propaga por semilla y por división de matas. Cuando se propagan por semilla, las plantas florecen hasta siete años después de la siembra, y por división de matas tardan 10 años en poder ser utilizadas como plantas madre. Esto explica el porqué $S$. reginae es una de las pocas especies florales para las cuales no hay cultivares uniformes. El desarrollo de un método de propagación in vitro podría contribuir a la selección de clones mejorados de esta especie, así como a su proliferación masiva (Ziv y Halevy, 1983).

La propagación de plantas in vitro a través de la embriogénesis somática (ES) ha sido establecida exitosamente para varias especies ornamentales monocotiledóneas. Previo al proceso de ES, generalmente se presenta la formación de proembriones somáticos (PES). Para $S$. reginae aún no se ha tenido éxito en la ES debido a que presenta serios problemas de oscurecimiento y poca respuesta de los explantes cultivados en la formación de PES (Ziv y Halevy, 1983).

Las primeras pruebas de micropropagación de $S$. reginae fueron hechas por Ziv y Halevy (1983) quienes indujeron la formación de brotes a partir de yemas vegetativas cultivadas en el medio MS (Murashige y Skoog, 1962) enriquecido con $1 \mathrm{~g} \mathrm{~L}^{-1}$ de carbón activado (CA). Hosni (2001) también cultivó meristemos de $S$. reginae en el medio MS y logró la inducción de brotes con una combinación de 6-bencilaminopurina (BAP) y ácido indolbutírico (AIB). Más tarde, Duarte de Oliveira et al. (2004) cultivaron segmentos foliares, yemas axilares y embriones maduros e inmaduros de plantas adultas de $S$. reginae, y encontraron que los embriones inmaduros lograron formar callos y estructuras semejantes a embrioides, pero no continuaron su desarrollo. 
Por ello, es importante hacer un estudio que permita la inducción de proembriones somáticos, como una fase previa al proceso de embriogénesis somática. El objetivo de este trabajo fue estudiar el efecto de diferentes concentraciones de sales del medio MS, sacarosa y 2,4-D, así como de dos condiciones de cultivo (luz y oscuridad), para inducir proembriones somáticos a partir de secciones del nudo cotiledonar de plántulas de $S$. reginae cultivadas in vitro.

\section{MATERIALES Y MÉTODOS}

El material vegetal consistió en semillas maduras de ave de paraíso (Strelitzia reginae Banks) obtenidas del rancho "El Colibrí" ubicado en Uruapan, Michoacán, México. Las semillas desprovistas del arilo se colocaron en un frasco con jabón antibacteriano (Member's Mark $®$ ) y se lavaron con agua corriente durante 15 min. Posteriormente, en la campana de flujo laminar horizontal $($ ALDER $\AA)$, se sumergieron en etanol $70 \%$ durante 1 min; después se colocaron en hipoclorito de sodio $1 \%$ por $10 \mathrm{~min}$, se enjuagaron dos veces con agua destilada esterilizada, y finalmente se colocaron en agua destilada esterilizada durante $48 \mathrm{~h}$ en condiciones de completa oscuridad a $4{ }^{\circ} \mathrm{C}$.

\section{Germinación in vitro de embriones cigóticos (EC)}

De las semillas desinfectadas se extrajeron los EC y, para inducir su germinación in vitro, se cultivaron en el medio de cultivo MS (Murashige y Skoog, 1962) a 100 $\%$, sin hormonas, y suplementado con $30 \mathrm{~g} \mathrm{~L}^{-1}$ de sacarosa $($ SIGMA $®)$ y $1 \mathrm{~g} \mathrm{~L}^{-1}$ de carbón activado (SIGMA ${ }^{\circledR}$ ). El pH se ajustó a $5.7 \pm 0.1$ con $\mathrm{NaOH}$ o $\mathrm{HCl} 0.1 \mathrm{~N}$, y el medio de cultivo se gelificó con $2 \mathrm{~g} \mathrm{~L}^{-1}$ de gelrite (SIG$\mathrm{MA} \otimes)$, y la esterilización del medio de cultivo se hizo en una autoclave vertical $(A E S A \otimes)$ a $121^{\circ} \mathrm{C}$ y $1.1 \mathrm{~kg} \mathrm{~cm}^{-2} \mathrm{de}$ presión durante $20 \mathrm{~min}$. Se usaron 80 frascos de vidrio de $80 \mathrm{~mL}$ de capacidad, y a cada uno se le agregó $20 \mathrm{~mL}$ de medio de cultivo; se colocaron cinco EC por frasco, para un total de $400 \mathrm{EC}$. Todos los cultivos se mantuvieron a una temperatura de $25 \pm 1{ }^{\circ} \mathrm{C}$, con un fotoperíodo de $16 \mathrm{~h}$ luz y 8 de oscuridad, con una intensidad lumínica de 2600 lux aproximadamente.

\section{Inducción de proembriones somáticos (PES) y análisis histológico}

Para inducir la formación de PES se utilizaron plántulas de $30 \mathrm{~d}$ de edad obtenidas por germinación in vitro de EC. De estas plántulas se extrajeron, como explantes, fragmentos del nudo cotiledonar de aproximadamente 0.8 $\mathrm{cm}^{2}$ y se cultivaron en el medio MS, el cual se gelificó con $2 \mathrm{~g} \mathrm{~L}^{-1}$ de gelrite (SIGMA $\circledast$ ). Los factores evaluados para la inducción de PES fueron: dos concentraciones del medio de cultivo MS (100\% y $50 \%$ ), dos concentraciones de sacarosa $\left(10\right.$ y $\left.30 \mathrm{~g} \mathrm{~L}^{-1}\right)$, cinco concentraciones de ácido 2,4-diclorofenoxiacético $(0.0,0.5,1.0,1.5$ y 2.0 $\mathrm{mg} \mathrm{L}^{-1}$ ), y dos condiciones de cultivo (luz y oscuridad). En todos los casos se agregó $0.1 \mathrm{~g} \mathrm{~L}^{-1}$ de carbón activado al medio MS.

Los PES formados se transfirieron a un medio de germinación, el cual consistió en el medio MS (50\%), suplementado con $50 \mathrm{~g} \mathrm{~L}^{-1}$ de sacarosa y gelificado con $8 \mathrm{~g}$ $\mathrm{L}^{-1}$ de agar bacteriológico $(\mathrm{BIOXON} \circledast)$.

Para el análisis histológico se tomaron muestras de PES y de callos embriogénicos (CE), con la metodología propuesta por Sass (1958). Se hicieron cortes transversales $(10 \mu \mathrm{m})$ del CE y longitudinales al eje mayor de los PES. Los cortes histológicos fueron montados en resina sintética y analizados bajo un microscopio óptico compuesto Axioskop 2 (Zeiss ${ }^{\circledR}$ ) acoplado a un sistema de captura digital de imágenes AxioCam MRc5.

\section{Diseño experimental y análisis estadístico}

Los datos del número de PES inducidos por tratamiento después de $150 \mathrm{~d}$ de iniciado el cultivo, se sometieron a un análisis de varianza y a la prueba de rangos múltiples de Tukey (Steel y Torrie, 1985), conforme a un diseño experimental completamente al azar con arreglo tetrafactorial $2 \times 2 \times 5 \times 2$. Los 40 tratamientos con 10 repeticiones cada uno, se distribuyeron en frascos de cultivo, cada uno con cinco explantes; cada explante fue considerado como una unidad experimental. Los datos fueron transformados mediante raíz cuadrada y se analizaron con el programa estadístico SAS versión 8.0 (SAS Institute, 1999).

\section{RESULTADOS Y DISCUSIÓN}

\section{Germinación in vitro de embriones cigóticos (EC)}

En esta investigación se obtuvo $100 \%$ de germinación de los EC a los $4 \mathrm{~d}$ de iniciado el cultivo, posiblemente porque la madurez fisiológica y las condiciones bajo las cuales fueron cultivados in vitro, favorecieron dicho proceso. Estos resultados coinciden con los reportados por Duarte de Oliveira et al. (2004), quienes observaron que en embriones maduros e inmaduros de $S$. reginae solamente los embriones maduros presentaron germinación, mientras que los embriones inmaduros únicamente formaron callos y estructuras parecidas a embrioides, y no mostraron desarrollo posterior. 


\section{Inducción de proembriones somáticos (PES) y análisis histológico}

A cinco meses de iniciado el cultivo, se observó en los explantes la formación de masas globulares de aspecto similar a PES. Los factores que influyeron en el número de PES inducidos por tratamiento fueron: las condiciones de cultivo, así como las interacciones medio de cultivosacarosa (A x B) y medio de cultivo-sacarosa-condiciones de cultivo (A x B x C) (Cuadro 1).

Según Ziv y Halevy (1983) y Hosni (2001), la incubación de cultivos en completa oscuridad por $10 \mathrm{~d}$ es esencial para prevenir el oscurecimiento, y así favorecer la formación de brotes en $S$. reginae. El efecto del 2,4-D podría estar también relacionado con la inducción de respuesta morfogénica, ya que la degradación de esta auxina es más lenta cuando los explantes se incuban en la oscuridad que en luz (Arzate et al., 1998). Esto podría explicar porqué en la presente investigación sólo los cultivos en condiciones de oscuridad y en presencia de 2,4-D formaron PES, aún cuando los explantes se hubieran oscurecido. Sin embargo, no se encontraron diferencias significativas entre las concentraciones evaluadas de 2,4-D (Cuadro 1).

Como el medio MS proveé los seis nutrimentos principales ( $\mathrm{N}, \mathrm{P}, \mathrm{K}, \mathrm{Ca}, \mathrm{Mg}$ y $\mathrm{S})$, hace suponer que el medio de cultivo es uno de los factores clave en la morfogénesis de células que crecen in vitro, de manera que una reducción en su concentración puede afectar el desarrollo morfogénico (Marschner, 1995; citado por Ramage y Williams, 2002). Lo anterior se observó en esta investigación ya que con el medio MS a $100 \%$ se obtuvieron 10 PES, mientras que en la concentración de $50 \%$ sólo se observaron cinco (Cuadro 1).

Se sabe también que los carbohidratos suplementados al medio de cultivo pueden tener múltiples funciones, como la histodiferenciación de PES, por medio de la regulación génica (Lipavská et al., 2000). Según Körbes y Droste (2005), la concentración de sacarosa puede afectar la inducción morfogénica, tanto como fuente nutritiva como al regular el potencial osmótico del medio de cultivo, puesto que la concentración de sacarosa a $3 \%$ estimuló la proliferación celular en Heliconia rostrata (Torres et $a l .$, 2005). Resultados similares se detectaron en este estudio, ya que con $30 \mathrm{~g} \mathrm{~L}^{-1}$ de sacarosa se logró obtener el $73.4 \%$ de PES inducidos (Cuadro 1), lo que al parecer muestra un efecto conjunto de la fuente de carbono y el medio de cultivo. Ambos factores (medio de cultivo y sacarosa) fueron estadísticamente similares en la prueba de Tukey $(\alpha=0.05)$, pero su interacción mostró un efecto significativo en la prueba de F (Cuadro 1), por lo que la suma de estos dos factores, aunado al de las condiciones de cultivo, permiten explicar las diferencias significativas observadas para la interacción A x B x C, en la inducción de PES.

Cuadro 1. Promedio del número de proembriones somáticos (PES) inducidos en $S$. reginae, en respuesta al medio de cultivo, sacarosa, condiciones de cultivo y 2,4-D. Los valores fueron obtenidos a los $150 \mathrm{~d}$ después de iniciado el cultivo.

\begin{tabular}{|c|c|c|c|}
\hline Factor de estudio & Nivel & $\begin{array}{l}\text { Número de } \\
\text { proembriones } \\
\text { somáticos } \\
\text { formados }(\%) \\
\end{array}$ & $\mathrm{F}$ \\
\hline \multirow{2}{*}{$\begin{array}{l}\text { Medio de cultivo } \\
\text { (\%) (A) }\end{array}$} & 100 & $10(66.7) \mathrm{a}$ & \multirow[t]{2}{*}{$2.03 \mathrm{~ns}$} \\
\hline & 50 & $5(33.3) \mathrm{a}$ & \\
\hline \multirow{2}{*}{$\begin{array}{l}\text { Sacarosa }\left(\mathrm{g} \mathrm{L}^{-1}\right) \\
\text { (B) }\end{array}$} & 10 & $4(26.6) \mathrm{a}$ & \multirow[t]{2}{*}{$3.97 \mathrm{~ns}$} \\
\hline & 30 & $11(73.4) \mathrm{a}$ & \\
\hline \multirow{3}{*}{$\begin{array}{l}\text { Condiciones de } \\
\text { cultivo (C) }\end{array}$} & Luz & $0(0) \mathrm{a}$ & \multirow[t]{2}{*}{$18.24 * * *$} \\
\hline & Oscuridad & $15(100) \mathrm{b}$ & \\
\hline & 0.0 & $0(0) \mathrm{a}$ & \multirow[t]{5}{*}{$2.23 \mathrm{~ns}$} \\
\hline \multirow{4}{*}{$\begin{array}{l}\text { 2, 4-D }\left(\mathrm{mg} \mathrm{L}^{-1}\right) \\
\text { (D) }\end{array}$} & 0.5 & $4(26.6) \mathrm{a}$ & \\
\hline & 1.0 & $5(33.4) \mathrm{a}$ & \\
\hline & 1.5 & $5(33.4) \mathrm{a}$ & \\
\hline & 2.0 & $1(6.6) \mathrm{a}$ & \\
\hline $\mathrm{A} \times \mathrm{B}$ & & & $6.57 * *$ \\
\hline$A \times B \times C$ & & & $6.57 * *$ \\
\hline
\end{tabular}

** $\mathrm{P}=\leq 0.01, * * *=\leq 0.001, \mathrm{~ns}=$ no significativo. Medias con la misma letra no son estadísticamente diferentes (Tukey, 0.05). Coeficiente de variación $=12.51 \%$

Los 15 PES se indujeron a partir de CE, el cual tuvo un peso promedio de $75.4 \mathrm{mg}$ y una longitud de $1 \mathrm{~cm}$. El CE obtenido fue de consistencia compacta, de apariencia blanco-cremosa y con estructuras globulares en la superficie (Figura 1A), similares a las de PES. Histológicamente, el callo estuvo formado por células parenquimatosas en tejido compuesto, sin espacios intercelulares y con células alargadas en la periferia (Figura 1B). Se observó, además, que las estructuras globulares se originaron de forma directa de los explantes (Figura 1C) y mostraron la apariencia de un proembrión somático (PES) en estadio globular, que se originaron del tejido vascular (Figura 1D). Los PES continuaron su crecimiento y formaron estructuras alargadas de 5 a $6 \mathrm{~mm}$ de longitud (Figura 1E), cuyo extremo distal presentó un conjunto de células meristemáticas, comparables a las de un meristemo apical de raíz pero sin centro quiescente (Figura $1 \mathrm{~F}$ ). Los cortes histológicos no evidenciaron la presencia de un meristemo apical de brote.

Lai et al. (1995) reportaron que aun cuando los embriones somáticos acumulan altos niveles de nutrientes, su vigor para germinar es mucho menor que el de las semillas comunes. Este hecho frecuentemente se atribuye a 
que los embriones somáticos pueden tener un limitado nivel de reacciones anabólicas que puede ocasionar una lenta elongación de radícula e hipocotilo, y a que el meristemo del brote en los embriones somáticos puede desarrollarse anormalmente durante la maduración, como también fue observado por Balbão et al. (2001), quienes cultivaron meristemos apicales de plántulas de Musa spp. en medio MS con 2,4-D, ANA y Picloram, y reportaron que sólo el 2,4-D fue capaz de bloquear el desarrollo normal de los meristemos utilizados.

En esta investigación los PES inducidos no lograron germinar, posiblemente por una exposición prolongada al 2,4-D que haya producido un efecto negativo en el desarrollo del meristemo, el cual empieza a diferenciarse en el estadio globular. Además en este estadio el transporte polar de una auxina es esencial para establecer la polaridad del embrión, la cual puede ser afectada si existe un incremento de auxina a nivel endógeno, como consecuencia de su adición al medio de cultivo

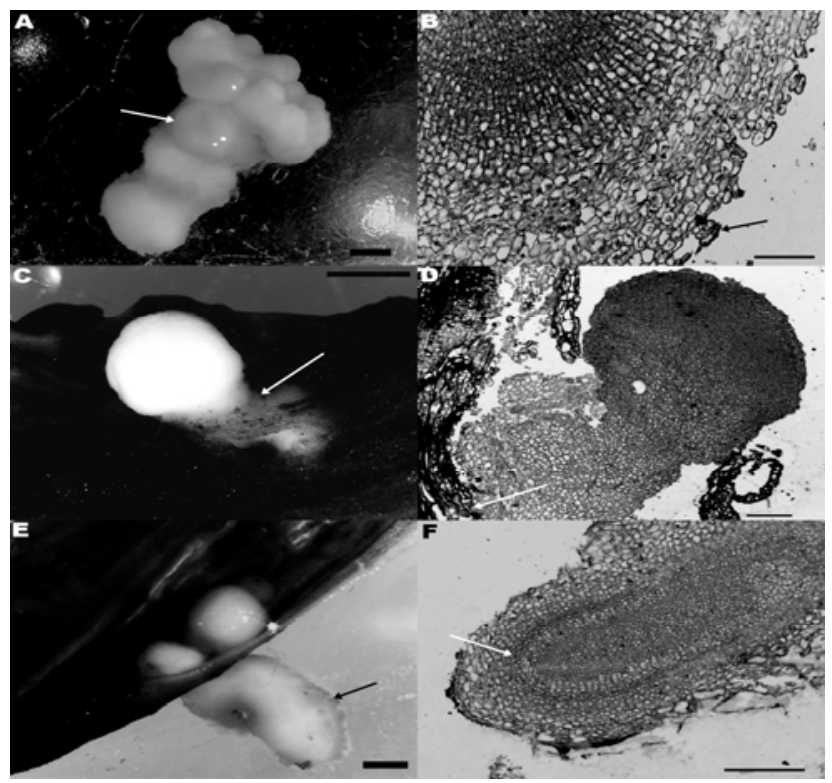

Figura 1. (A) Callo embriogénico de $S$. reginae formado en condiciones de oscuridad, en medio MS $100 \%$, suplementado con 2,4-D 0.5 mg $\mathrm{L}^{-1}$, y sacarosa $30 \mathrm{~g} \mathrm{~L}^{-1}, 150$ días después de iniciado el cultivo. La flecha señala la estructura globular similar a la de un proembrión somático (PES); barra $=100 \mu \mathrm{M}$. (B) Corte histológico del callo embriogénico presentado en $\mathrm{A}$, mostrando las células alargadas localizadas en la periferia del mismo (flecha); barra $=100 \mu \mathrm{M}$. (C) Desarrollo de un PES en estadio globular, $y$ la flecha indica la formación directa a partir del explante; barra $=1000 \mu \mathrm{M}$. (D) Corte histológico del PES presentado en $\mathrm{C}$, $\mathrm{y}$ la flecha señala el desarrollo del PES a partir de tejido vascular; barra $=200 \mu$ M. (E) Presencia de un PES indicado por la flecha, desarrollado de forma directa y aparentemente separado del tejido original; barra $=500 \mu \mathrm{M}$. (F) Corte histológico del PES presentado en $E$, y la flecha señala una organización celular comparable a la de un meristemo apical de raíz; barra $=200 \mu \mathrm{M}$.
Con base en lo anterior, es probable que los PES aquí obtenidos sean el resultado de una embriogénesis alterada en los primeros estadios de desarrollo, al no presentar el establecimiento de dicha polaridad (Fischer y Neuhaus, 1996; citados por Balbão et al., 2001).

En conclusión, en este trabajo de investigación se logró $100 \%$ de germinación de los embriones cigóticos. Las condiciones de cultivo (luz u oscuridad), así como las interacciones medio de cultivo x sacarosa y medio de cultivo $\mathrm{x}$ sacarosa $\mathrm{x}$ condiciones de cultivo, tuvieron efectos significativos en el número de PES inducidos en $S$. reginae. La ausencia de 2,4-D no favoreció la inducción de PES. La mejor inducción de PES se vio favorecida por el efecto sinérgico del medio de cultivo MS (100\%) adicionado con sacarosa $\left(30 \mathrm{~g} \mathrm{~L}^{-1}\right)$, y en condiciones de oscuridad.

\section{BIBLIOGRAFÍA}

Arzate F A M, T Nakazaki, T Tanisaka (1998) Production of diploid and triploid interspecific hybrids between Lilium concolor and L. longiflorum by ovary slice culture. Plant Breed. 117:479484.

Balbão F S, B A Da Gloria, A P M Rodríguez (2001) Histological changes in banana explants, cv. Nanicão (Musa spp., Group AAA), submitted to different auxins for induction of somatic embryogenesis. Rev. Bras. Bot. 24:595-602.

Duarte de Oliveira P P, R Paiva, M Pasqual, L V Paiva (2004) Estabelecimento in vitro de Estrelícia (Strelitzia reginae Banks). Ciência e Agrotec. 28:1031-1037.

Hosni A M (2001) Increasing the potential of in vitro propagation of Strelitzia reginae Aiton. Arab. Universities J. Agri. Sci. 9:839-852.

Körbes A P, A Droste (2005) Carbon sources and polyethylene glycol on soybean somatic embryo conversion. Pesq. Agropec. Bras. 40:211-216.

Lai F M, C G Lecoutex, B D Mc Kersie (1995) Germination of alfalfa (Medicago sativa L.) seeds and desiccated somatic embryos.1. Mobilization of storage reserves. Plant Physiol. 145:507-513.

Lipavská H, H Svobodová, J Albrechtová, L Kumstýrová, M Vágner, Z Vondráková (2000) Carbohydrate status during somatic embryo maturation in Norway spruce. In Vitro Cell Develop. Biol. Plant. 36:260-267.

Murashige T, F Skoog (1962) A revised medium for rapid growth and bioassays with tobacco cultures. Physiol. Plant. 15:473-497.

Ramage C M, R R Williams (2002) Mineral nutrition and plant morphogenesis. In Vitro Cell Develop. Biol. Plant 38: 116124.

SAS (1999) SAS User's guide: Statistics version 8.0. Cary, NC: SAS Institute Inc.

Sass E J (1958) Botanical Microtechniques. Iowa State University Press. 3rd ed. USA. 277 p.

Steel R G, Torrie (1985) Bioestadística. Principios y Procedimientos. 2a ed. Editorial Mc Graw - Hill S.A. México. pp:179-180.

Torres C A, F D Duval, D G Ribeiro, A F F Barros, F A D Aragão (2005) Efeito da sacarose, cinetina, isopentil adenina e zeatina no desenvolvimento de embriões de Heliconia rostrata in vitro. Hort. Brasil. 23:789-792.

Ziv M, A H Halevy (1983) Control of oxidative browning and in vitro propagation of Strelitzia reginae. Hort. Sci. 18:434-436. 